\title{
Potassium Nitrate Alters Buffalograss Bur Permeability
}

\author{
Katherine Kreuser and William C. Kreuser \\ Department of Agronomy and Horticulture, University of Nebraska Lincoln, \\ Lincoln, NE 68583
}

\section{Gautam Sarath}

U.S. Department of Agriculture-Agricultural Research Service, Grain, Forage and Bioenergy Research Unit and Department of Agronomy and Horticulture, University of Nebraska, Lincoln, NE

\section{Keenan L. Amundsen ${ }^{1}$}

Department of Agronomy and Horticulture, University of Nebraska Lincoln, Lincoln, NE 68583

Additional index words. buffalograss, seed dormancy, germination, potassium nitrate, postharvest treatment

\begin{abstract}
Buffalograss is a warm-season, dioecious grass species yielding burs, which are routinely used for field plantings. The pistillate plants bear the burs containing 1-5 caryopses. Isolated caryopses readily germinate, but caryopses contained within burs exhibit strong dormancy, suggesting that burs inhibit germination. Priming burs with low concentrations of potassium nitrate $\left(\mathrm{KNO}_{3}\right)$ is used as an industry standard to improve germination. Seed dormancy and germination in many species are strongly influenced by endogenous hormone levels, principally abscisic acid (ABA) and gibberellic acid (GA). It follows that buffalograss seed dormancy might be induced or overcome by altering the ratio of ABA to GA. The objectives of this research were 1) to contrast the effects of priming with $\mathrm{KNO}_{3}$ or water on bur germination, 2) to study how these treatments affected hormone profiles, specifically the ABA/GA ratios in the burs, and $3)$ to quantify treatment effects on the water permeability of the burs. Hormone profiles were analyzed following four postharvest seed-soaking treatments (24-hour $0.05 \mathrm{M} \mathrm{KNO}_{3}$, 24-hour $\mathrm{H}_{2} \mathrm{O}$, 48-hour $0.05 \mathrm{M} \mathrm{KNO}_{3}$, and 48-hour $\mathrm{H}_{2} \mathrm{O}$ ). Water infiltration tests on nontreated, 24-hour $\mathrm{H}_{2} \mathrm{O}$-treated, and 24-hour 0.05 M $\mathrm{KNO}_{3}$-treated seeds were also conducted. Inconclusive hormone profiling results did not support the hypothesis that $\mathrm{KNO}_{3}$ postharvest treatment raises GA levels to encourage germination. Instead, our data support changes in seed morphology following $\mathrm{KNO}_{3}$ postharvest seed treatments which alter water permeability of the seedcoat leading to increased germination.
\end{abstract}

Buffalograss [Buchloë dactyloides (Nutt.) Engelm. Syn. Bouteloua dactyloides (Nutt.)

\footnotetext{
Received for publication 8 July 2016. Accepted for publication 17 Oct. 2016.

The U.S. Department of Agriculture (USDA) prohibits discrimination in all its programs and activities on the basis of race, color, national origin, age, disability, and where applicable, sex, marital status, familial status, parental status, religion, sexual orientation, genetic information, political beliefs, reprisal, or because all or part of an individual's income is derived from any public assistance program. (Not all prohibited bases apply to all programs.) Persons with disabilities who require alternative means for communication of program information (Braille, large print, audiotape, etc.) should contact USDA's TARGET Center at (202) 720-2600 (voice and TDD). To file a complaint of discrimination, write to USDA, Director, Office of Civil Rights, 1400 Independence Avenue, Southwest, Washington, DC 20250-9410, or call (800) 795-3272 (voice) or (202) 720-6382 (TDD). USDA is an equal opportunity provider and employer. We thank the United States Golf Association for partially funding this research.

${ }^{1}$ Corresponding author. E-mail: kamundsen2@unl. edu.
}

Columbus], a dioecious, warm-season grass native to the U.S. plains region, is touted for characteristics like drought tolerance, winterhardiness, and requiring minimal fertility and pest control inputs compared with other turfgrass species (Pozarnsky, 1983; Wenger, 1940; Wenger, 1943). Ornamental native grasses are used for a variety of landscape purposes that include beautification, erosion control, landscape restoration, and turfgrass alternatives. However, researchers, agriculturalists, and others have discovered the challenges in reliable seed germination of warm-season grasses, many of which are also native to the Great Plains region (Baskin and Baskin, 1998).

A buffalograss seed, called a bur, consists of 1-5 caryopses tightly wrapped in a bur coat. When planted without any seed treatment, bur germination rates are $<30 \%$, making stand establishment from seed a difficult task. However, nontreated caryopses (removed in a deburring process) will germinate at high rates $(>90 \%)$, but remain viable for only short periods of time, and significant losses can occur during the timeconsuming deburring process. In addition, deburring adds to postharvest seed production costs and is not economically practical for the buffalograss seed producer's industry. To improve buffalograss establishment and use, seeds are primed, a postharvest hydration seed treatment that is commonly used to increase seed germination (Hilhorst, 1990; Wenger, 1943). Industry professionals typically soak harvested burs in a $0.05 \mathrm{M} \mathrm{KNO}_{3}$ solution followed by a moist chill treatment at $5{ }^{\circ} \mathrm{C}$ for 5 weeks, a treatment adapted from Wenger (1941) (R. Fritz, personal communication). The $\mathrm{KNO}_{3}$ treatment adds about $\$ 0.50$ per pound in seed costs for consumers, but these costs are offset by significant improvement in seed germination when compared with untreated burs. However, little is understood about the physiology of the bur- $\mathrm{KNO}_{3}$ interaction, how priming improves germination in buffalograss, and what factors contribute to seed dormancy in this species.

Seed dormancy occurs when complete germination is blocked in viable seeds grown under favorable conditions (Finch-Savage and Leubner-Metzger, 2006). A dormant seed cannot germinate over a period of time even though advantageous physical and environmental conditions may exist (Bewley, 1997; Hilhorst et al., 2010; Hoang et al., 2013). Over the course of time, seed dormancy has likely evolved to allow germination to occur and seedlings to establish when conditions are suitable.

Unlike economically important crops that lack dormancy from selection and breeding, most native warm-season forage grasses have not been heavily altered by the breeding process, and still possess characteristics like those of wild varieties (Adkins et al., 2002). Seed dormancy has been categorized into five classes: physiological (PD), morphological (MD), morphophysiological (MPD), physical (PY), and combinational (PY + PD). Some classes fall under a coat-imposed dormancy, whereas others result from a problem with the embryo, caused by genetics, immaturity, or a promoter imbalance due to environmental conditions (Adkins et al., 2002; Bewley and Black, 1985; Foley, 1999; Villiers and Wareing, 1964). Physiological dormancy, a seedcoatimposed type of dormancy, is divided into deep and nondeep dormancy. The difference between deep and nondeep PD is determined by growth response of the excised embryo. If the excised embryo grows abnormally or not at all, the dormancy is categorized as deep; however, if the embryo grows normally, the dormancy is classified as nondeep (Baskin and Baskin, 2004; Finch-Savage and Leubner-Metzger, 2006). In nondeep PD, the seedcoat prevents water uptake, gas exchange, and/or impedes the embryos' ability to expand (Adkins et al., 2002). In amenity grasses, it is common to find tissue enveloping the embryo, as in the bur of buffalograss, which could inhibit oxygen uptake and carbon dioxide release (Adkins et al., 2002), and thereby contribute to PD. To break PD, several months of warm or cold stratification of seeds or seed-containing structures are required. Nondeep PD, the type of 
dormancy observed in buffalograss (FinchSavage and Leubner-Metzger, 2006), can be overcome by GA treatments, scarification, warm or cold stratification, postharvest ripening in cold storage, fire, heat, or smoke, in several species, although such treatments may not effectively overcome dormancy in all seeds. Salt marsh grass, Distichlis spicata, is similarly treated with nitrate to overcome hormonal control of seed dormancy (Amen et al., 1970). Also, for some species, initial promotion of germination rates induced by external treatments may decrease significantly under storage.

The plant hormones ABA and GA play significant and well-known roles in seed dormancy and germination processes (FinchSavage and Leubner-Metzger, 2006; Hilhorst et al., 2010; Hoang et al., 2013; RodriguezGarcia, et al., 2009). Relatively high levels of ABA promote dormancy, and release from dormancy results in the decline of ABA levels and an increase in GA levels, suggesting the $\mathrm{ABA} / \mathrm{GA}$ ratio influences seed germination (Bewley, 1997; FinchSavage and Leubner-Metzger, 2006; Villiers and Wareing, 1964). In Arabidopsis, germination promoted by increasing GA content weakens the seed tissue around the radical (Ibarra et al., 2016; Kucera et al., 2005). However, there is no information currently available on plant hormone status in buffalograss burs or caryopses.

Several factors likely contribute to low germination rates in buffalograss. Ahring and Todd (1977) extracted uncharacterized oils from buffalograss burs. Soaking deburred caryopses in the extracted oil-reduced germination by $47 \%$, and furthermore, plant growth was reduced by dipping the root tips in the oils (Ahring and Todd, 1977). However, from these studies it is not clear if the oil is at high-enough concentrations within the bur coat to impede germination. Crocker (1916) suggested that seed structure could inhibit the exchange of oxygen and carbon dioxide or prevent water absorption into the seed, effectively slowing the germination process (Crocker, 1916). The objectives of our study were to compare the effectiveness of $\mathrm{KNO}_{3}$ and water postharvest seed treatments for increased germination, to study how the soaking treatments affected hormone profiles, specifically the ABA/GA ratios in the burs, and to quantify treatment effects on water permeability of the bur. The intent was to gain a deeper physiological understanding of seed dormancy in this important amenity grass.

\section{Materials and Methods}

Hormone profiling study. Seed hormone concentration and germination percentage of two buffalograss accessions NE07-01 and Sundancer were measured in response to four different soaking treatments. Soaking treatments included 24 or $48 \mathrm{~h}$ in distilled $\mathrm{H}_{2} \mathrm{O}$, or $0.05 \mathrm{M} \mathrm{KNO}_{3}$, and a nontreated control. Seeds were placed in cloth bags and immersed into the respective solutions using weights to ensure submersion of the seeds. After the duration of the soaking treatment was completed, excess solution was removed using a strainer, and the burs were cold-stratified by placing in a $5{ }^{\circ} \mathrm{C}$ refrigerator for 5 weeks (R. Fritz, personal communication). All treatments were replicated three times and the entire study was repeated twice at the University of Nebraska-Lincoln between the fall of 2014 and the spring of 2015. A subset of $10 \mathrm{~g}$ of seeds was removed from each treatment and used for hormone profiling, and another subset of 300 seeds was used for germination tests ( 100 seeds per replicate). For hormone profiling, the procedure was adapted from Luttgeharm et al. (2015). Seeds were immediately flash frozen in liquid nitrogen and placed in a $-80{ }^{\circ} \mathrm{C}$ freezer in BLUE $\mathrm{MAX}^{\mathrm{TM}}$ 50-mL Polypropylene Conical Tubes (Thermo Fisher Scientific, Waltham, MA). Seeds were fine milled using a 6870 Freezer Mill cryogenic grinder (Spex Sample Prep, Metuchen, NJ), and kept at $-80{ }^{\circ} \mathrm{C}$ until use. A $50 \mathrm{mg}$ aliquot of each sample was transferred to 2-mL screw-cap tubes while keeping tissue frozen, and $50 \mu \mathrm{L}$ of internal standard solution containing $5 \mathrm{ng}$ of each of the following deuterated standards: d6salicylic acid (SA), d5-zeatin, d6-ABA, d2GA4, and d2-JA. Five hundred microliters of extraction solvent (2-propanol:water:concentrated HCL (2:1:0.002), by volume) was added to each tube. The tubes were placed on a shaker at a speed of $100 \mathrm{rpm}$ for $30 \mathrm{~min}$ at $4{ }^{\circ} \mathrm{C}$, following which, $1 \mathrm{~mL}$ dichloromethane was added to each sample and shaken for $30 \mathrm{~min}$ in a cold room at $4{ }^{\circ} \mathrm{C}$. Samples were then placed into a refrigerated micro centrifuge at $4{ }^{\circ} \mathrm{C}$ and centrifuged at $13,000 g_{n}$ for $5 \mathrm{~min}$, which formed two phases with plant debris in between. Using a Pasteur pipette, $900 \mu \mathrm{L}$ of the solvent from the lower phase of each sample was transferred into a screw-cap vial. The solvent mixture was then concentrated with an evaporator using a stream of $\mathrm{N}_{2}$ gas. Samples were stored at $-20{ }^{\circ} \mathrm{C}$ until analyzed. Just before analysis, samples were redissolved in $100 \mu \mathrm{L}$ methanol and $900 \mu \mathrm{L}$ of buffer A (water $+0.1 \%$ formic acid and $0.3 \mathrm{~mm}$ ammonium formate $\mathrm{pH} 3.5$ ). Samples were subsequently analyzed by liquid chromatography-mass spectrometry as described elsewhere (Luttgeharm et al., 2015).

Caryopses hormone profiling. Caryopses used for hormone tests were separated from the burs using an electric coffee grinder (Krups GX4100 Coffee Grinder; Cookware Inc., Boston, MA), applying five 3-s pulses and subsequently using mill grain filters to isolate the caryopses (Riordan et al., 1997). Once separated, caryopses were imbibed in $0.05 \mathrm{M} \mathrm{KNO}_{3}$ or water as a control for $24 \mathrm{~h}$. The caryopses were immediately frozen at $-80{ }^{\circ} \mathrm{C}$ until they were fine milled using a cryogenic grinder (6870 Freezer Mill; Spex Sample Prep), and processed for hormone profiling as described above (Luttgeharm et al., 2015).

Germination tests. Germination procedures were adapted from Krizek et al. (2000) with the following modifications (2000). Triplicate samples of 100 burs each were hand counted following soaking and chilling treatments. Seeds were patted dry and then dried for $48 \mathrm{~h}$ on paper towels in

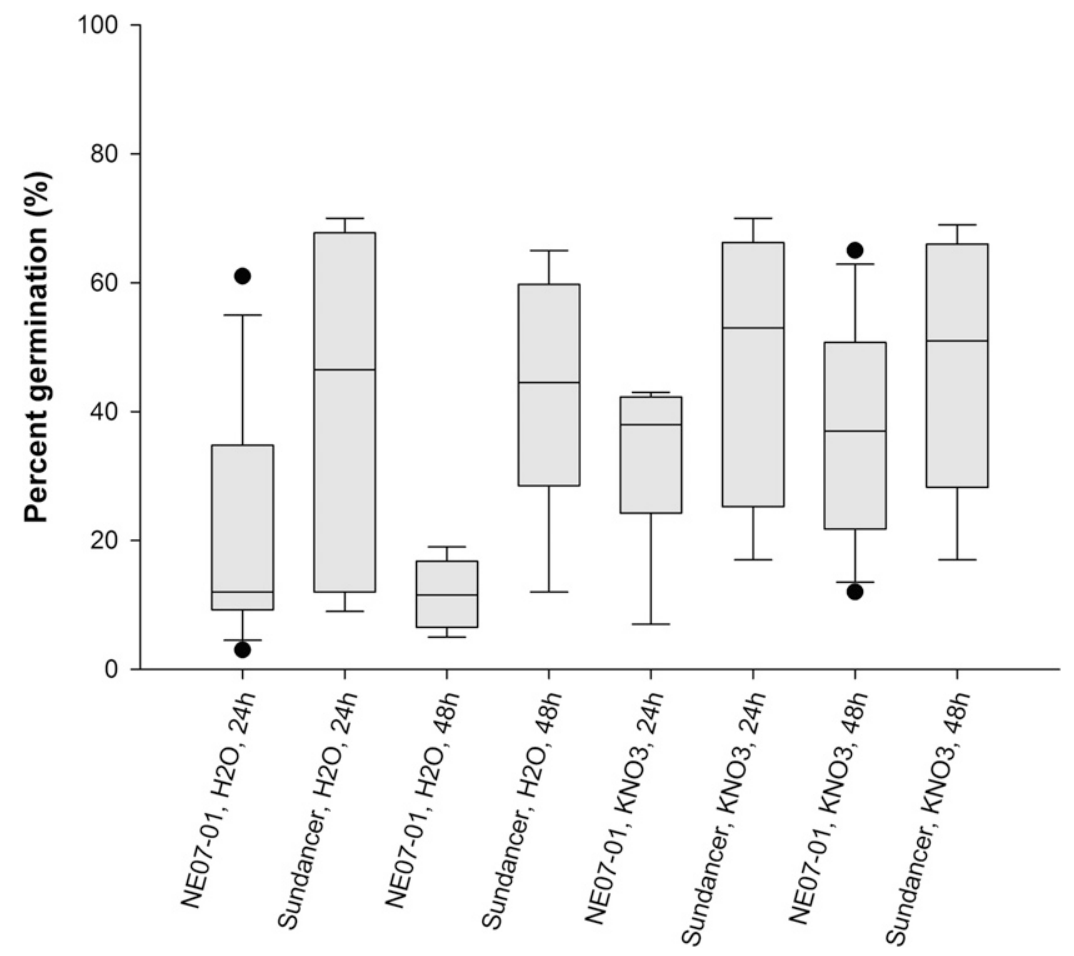

Fig. 1. The boxes represent the wide variability of percent buffalograss germination levels according to seed variety, seed treatment, and treatment duration. Error bars indicate the standard error of the mean. Black dots indicate outliers. 
a greenhouse with $20{ }^{\circ} \mathrm{C}$ night $/ 27{ }^{\circ} \mathrm{C}$ day temperatures. Upon drying, burs were immediately planted into no. 801 nursery pots in Fafard $^{\circledR}$ 3B Mix (Sun Gro Horticulture, Agawam, MA) (100 seeds per pot) in a greenhouse, and monitored weekly over $28 \mathrm{~d}$. Supplemental lighting provided a $16-\mathrm{h}$ daylength, and $20^{\circ} \mathrm{C}$ night $/ 27^{\circ} \mathrm{C}$ day temperatures were maintained in the greenhouse (Krizek et al., 2000).

Germination percentage of caryopses from nontreated burs was also calculated for reference. Caryopses from NE07-01 seed and Sundancer seed were separated from the bur coat as described above. One hundred to 150 caryopses separated from 40 burs of each variety were placed on filter paper, dampened with water, and placed in a completely dark cabinet and monitored once a day for $7 \mathrm{~d}$. Water was added as needed to keep the filter paper moist.

To explore secondary dormancy in buffalograss, seeds either treated with $0.05 \mathrm{M} \mathrm{KNO}_{3}$ for $24 \mathrm{~h}$ or nontreated were subjected $45^{\circ} \mathrm{C}$ in a dry oven for $21 \mathrm{~d}$, subsequently burs were subjected to three treatments: no soak, a 24-h water soak, or a 48 -h water soak. Burs were planted into a soil mix, and placed in a greenhouse to monitor germination for $21 \mathrm{~d}$.

Water infiltration tests on seed. Water infiltration tests were conducted to further understand treatment effects on intact burs. Burs were treated for $24 \mathrm{~h}$ in water or $0.05 \mathrm{M}$ $\mathrm{KNO}_{3}$ solution, or were not treated. Following treatments, three replicate samples of 10 seeds from each treatment were analyzed for water infiltration. Seeds were laid on their side on double-sided tape to prevent seed movement, and a $10 \mu \mathrm{L}$ drop of water was placed on each seed. Time was recorded from the placement of the initial drop of water onto the seed until the seed completely absorbed the water as adapted from the water drop penetration time test (Letey, 1969).

Seed dissection. NE07-01 seeds were soaked for 24 and $48 \mathrm{~h}$ in water and $0.05 \mathrm{M}$ $\mathrm{KNO}_{3}$ solution. After 24 and $48 \mathrm{~h}, 10$ seeds from each treatment were removed and sliced to expose both sides of the caryopses evenly within the bur. Photographs of the spliced seeds were taken with an AxioCam ICc 1 camera on a Stemi DV4 Zeiss dissecting scope at $32 x$ magnification (Zeiss USA, Thornwood, NY).

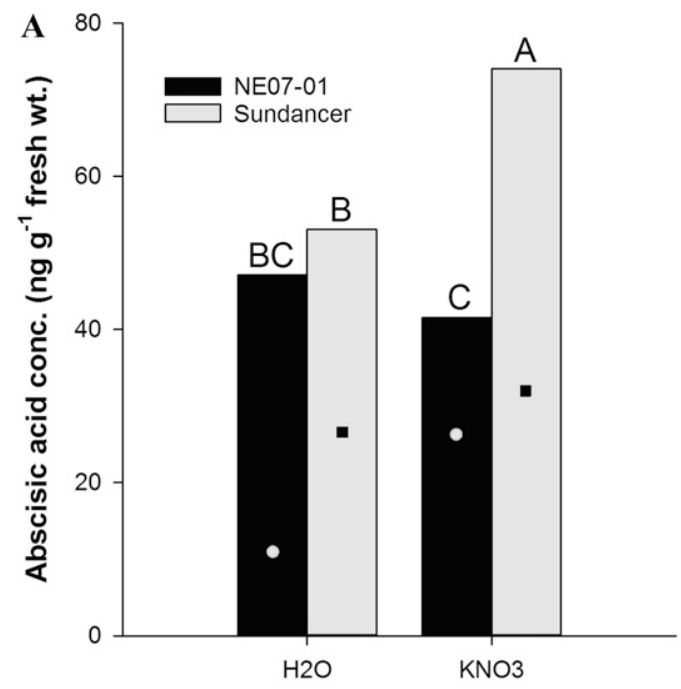

Soaking treatment

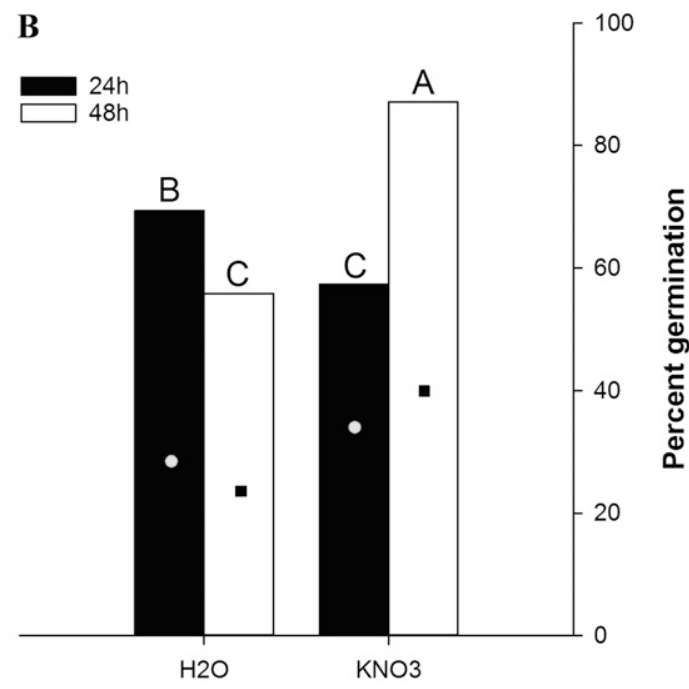

Soaking treatment

Fig. 2. Hormone profiles show the effects of (A) water- and $\mathrm{KNO}_{3}$-soaking treatments on two different buffalograss cultivars NE07-01 and Sundancer and (B) the soaking treatment duration, 24 and $48 \mathrm{~h}$, on abscisic acid concentrations (ng. $\mathrm{g}^{-1}$ fresh weight). Different upper case letters indicate significant differences among treatments and treatment duration by Student's $t$ test at the 0.05 level of significance.

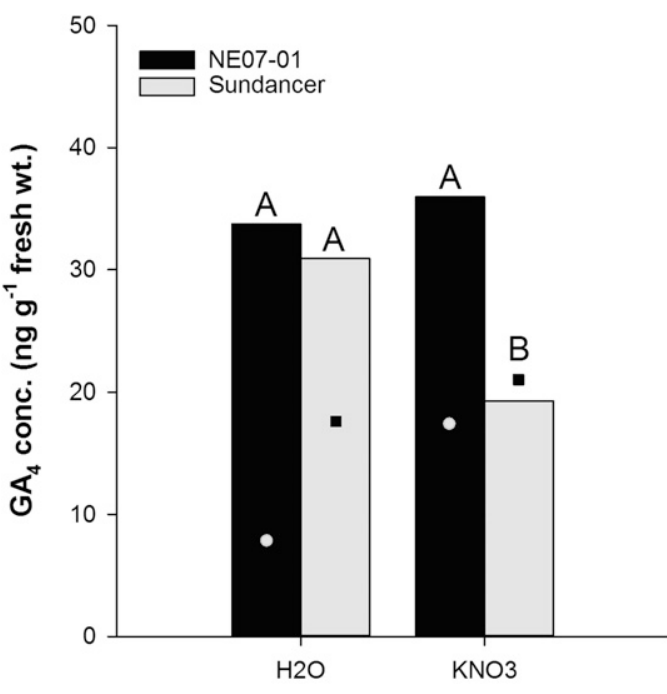

Soaking treatment

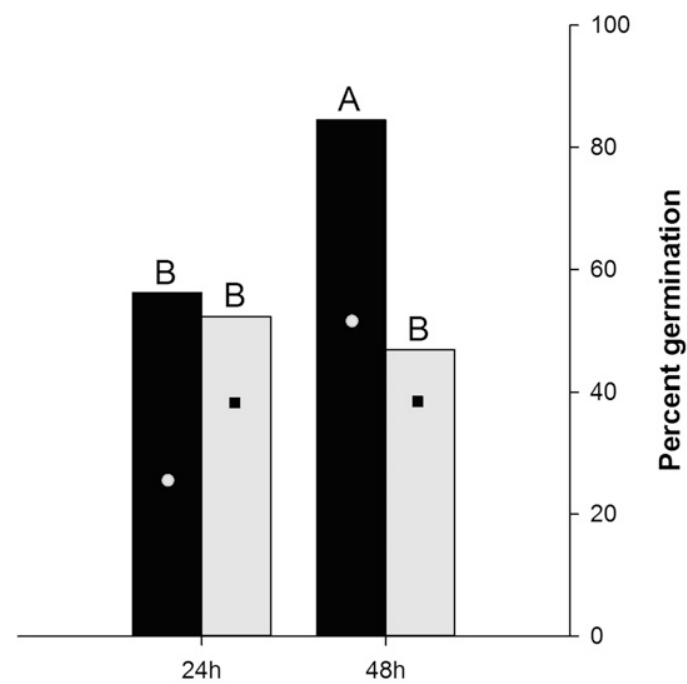

Soaking Duration

Fig. 3. Hormone profiles show the effects of the soaking treatments and duration treatments on gibberellic acid $\left(\mathrm{GA}_{4}\right)$ concentrations (ng. $\mathrm{g}^{-1}$ fresh weight) in Sundancer and NE07-01 seed varieties. Different upper case letters indicate significant difference among treatments and treatment duration by Student's $t$ test at the 0.05 level of significance. 
Statistical analyses. Experiments were completely randomized with three replicates. Significance of main effects and interactions were determined in JMP Version 12 (SAS Institute Inc., Cary, NC, 1989-2007) with the mixed procedure. Each run was treated as a random effect. Square root transformations were used as appropriate to satisfy the assumption of equal sample variance. Student's protected least significant difference was used to separate means and values were considered significant if they had a $P$ value $<0.05$.

\section{Results and Discussion}

Germination tests. A series of germination tests were conducted on $\mathrm{KNO}_{3}$, watertreated, and nontreated seeds. Nontreated seed germination data were not included due to the extremely low germination $(<10 \%)$ numbers that do not compare with the germination of seeds having undergone a water or nitrate soak. Germination tests showed no difference between treatments on Sundancer seed; however, there was an overall improvement trend in germination of $\mathrm{KNO}_{3}$-treated NE07-01 seeds (Fig. 1). Germination was most consistent among replicates for NE07-01 seeds water treated for $24 \mathrm{~h}$ and conversely, most variable for replicates of 24-h water-treated Sundancer seeds. These inconsistencies in germination for different seed lots from the same original source could arise from a number of different factors. For example, it could be attributed to environmental conditions during seed maturation on the mother plant and inherited genetics resulting in variations in germination (Finch-Savage and Leubner-Metzger, 2006), and potentially through the induction of secondary dormancy (Banovetz and Scheiner, 1994). Although it may be possible to overcome primary dormancy through physical or chemical treatments, in some seeds, secondary dormancy can be overcome by repeated treatment of nitrate (Hilhorst, 1998). Overall, germination results indicated a strong influence of plant genetics on the response of seed to treatments. Although seeds of NE07-01 responded to $\mathrm{KNO}_{3}$ treatments, Sundancer seeds did not, although Sundancer seeds appeared to possess greater germination as compared with the NE07-01 seeds (Fig. 1). The utility of these findings may result in considerable cost savings for producers and consumers if water treatments can be substituted for the standard $0.05 \mathrm{M}$ $\mathrm{KNO}_{3}$ treatments. At the physiological level, these data point to the genetic variability that exists within buffalograss accessions, strains and cultivars, and a greater need to decipher processes that control both primary and secondary dormancy in this species.

Secondary dormancy frequently occurs in seeds that have been primed and kept in storage for extended periods of time under inadequate light (Finkelstein et al., 2008; Ibarra et al., 2016). Although the physiological causes behind secondary dormancy are unclear, the net result is a significant loss in germination potential, even in ideal growing

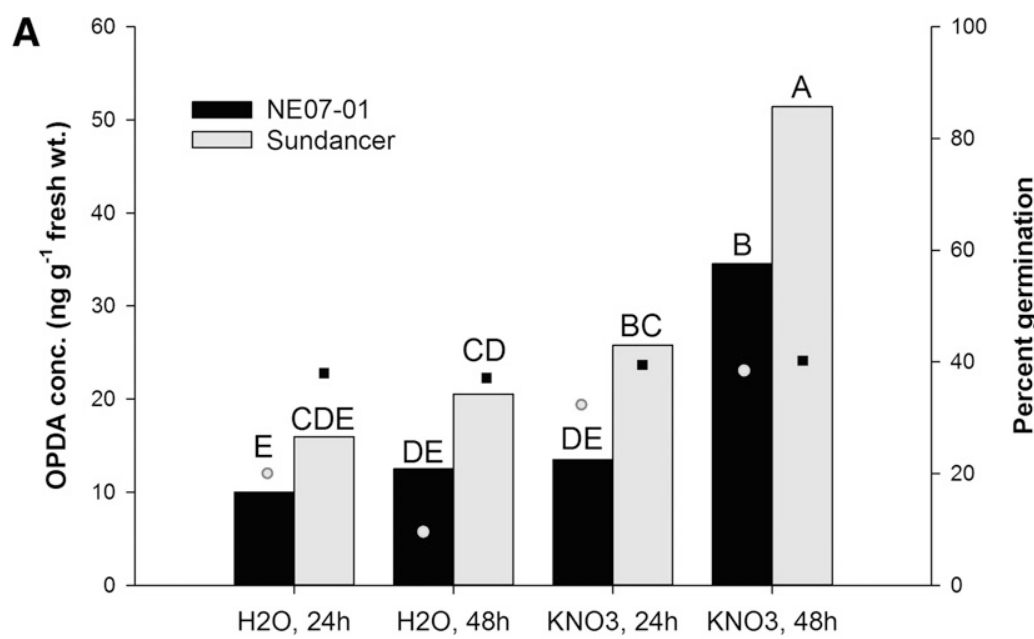

Soaking treatment and duration

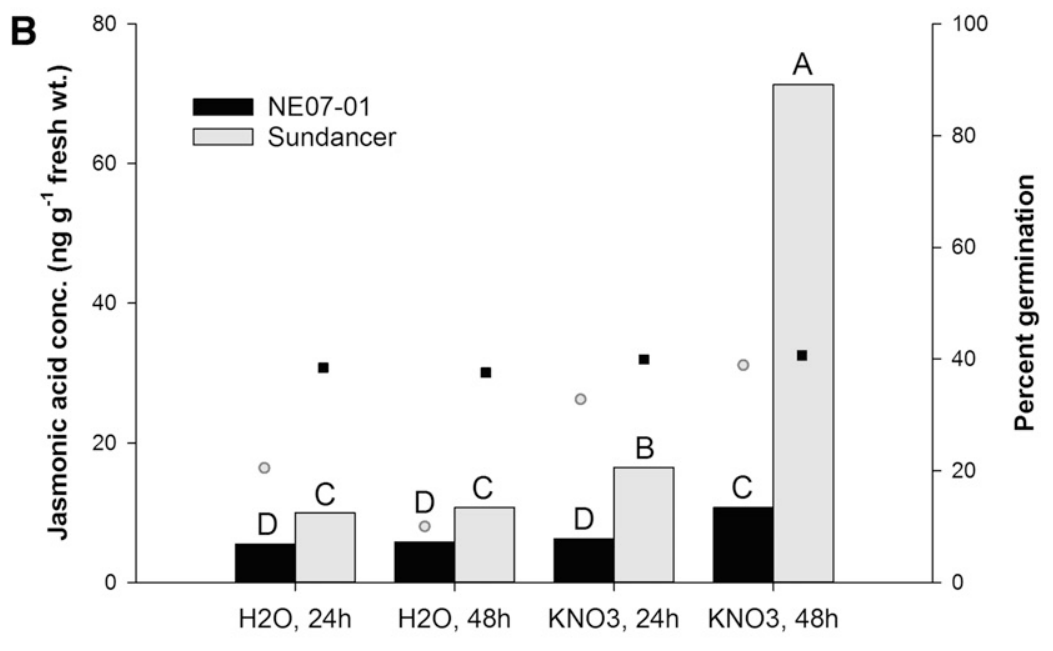

Soaking treatment and duration

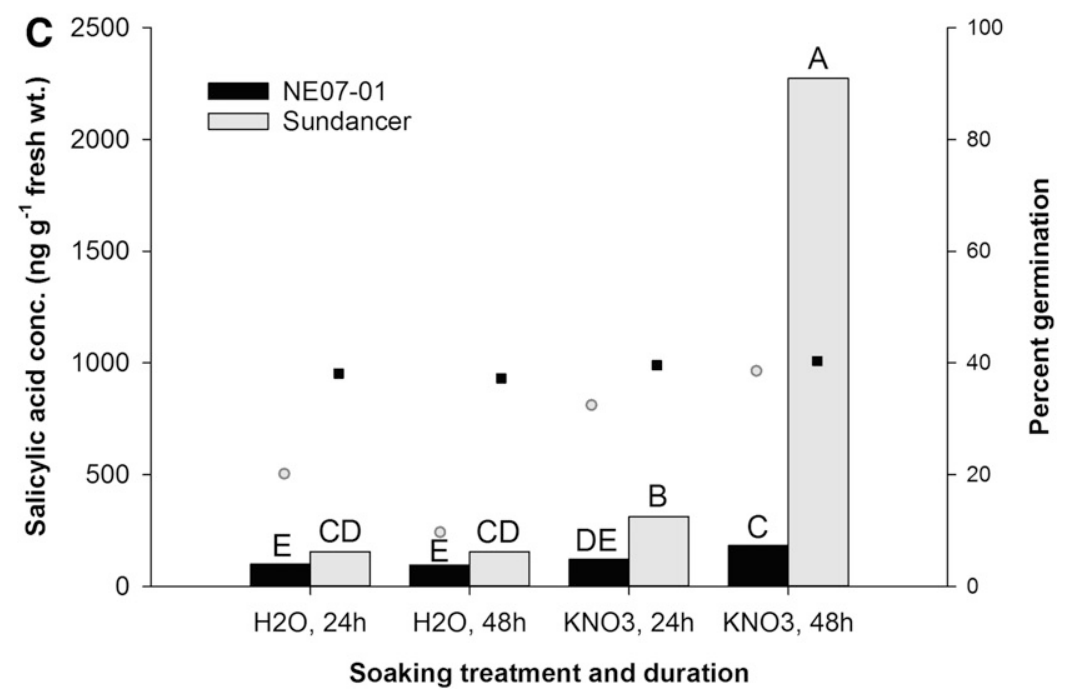

Fig. 4. Hormone profiles show the effects of $24 \mathrm{~h} \mathrm{H}_{2} \mathrm{O} / \mathrm{KNO}_{3}$ and $48 \mathrm{~h} \mathrm{H}_{2} \mathrm{O} / \mathrm{KNO}_{3}$ treatments on (A) $12-$ oxo-phytodienoic acid (OPDA), (B) jasmonic acid, and (C) salicylic acid concentrations (ng. $\mathrm{g}^{-1}$ fresh weight), respectively, in Sundancer and NE07-01 seed varieties. Different upper case letters indicate significant differences among treatments and treatment duration by Student's $t$ test at the 0.05 level of significance. Levels of hormones recorded at the $48-\mathrm{h} \mathrm{KNO}_{3}$ treatment do not reflect germination levels recorded at the same treatment and duration.

conditions (Hilhorst, 2007; Hilhorst et al., 2010; Hoang et al., 2013). For buffalograss NE07-01 seeds that were primed by a $24-\mathrm{h}$ water soak, and subjected to a heat treatment, $35^{\circ} \mathrm{C}$ for $14 \mathrm{~d}$, germination levels decreased from between $80 \%$ and $90 \%$ to between $20 \%$ 
and $70 \%$, suggesting the imposition of secondary dormancy by the heat treatment. When heat-treated seeds were reprimed by soaking for $48 \mathrm{~h}$ in water, seed germination increased to between $80 \%$ and $92 \%$, essentially indistinguishable from germination

Table 1. Average time in seconds recorded for burs to completely absorb $10 \mu \mathrm{L}$ of water according to the water or $0.5 \% \mathrm{KNO}_{3}$ treatment or nontreatment.

\begin{tabular}{lc}
\hline Treatment & Water infiltration(s) \\
\hline Nontreated & $1,564 \mathrm{a}^{\mathrm{y}}$ \\
$\mathrm{H}_{2} \mathrm{O}$ & $900 \mathrm{~b}$ \\
$\mathrm{KNO}_{3}$ & $731 \mathrm{c}$ \\
\hline
\end{tabular}

$\mathrm{KNO}_{3}=$ potassium nitrate.

${ }^{\mathrm{z}}$ Treatment of buffalograss seeds with water or $\mathrm{KNO}_{3}$ for $24 \mathrm{~h}$.

${ }^{\mathrm{y}}$ Different letters indicate significant difference among time by Student's $t$ test at the 0.05 level of significance. rates observed after initial priming. These data support the occurrence of secondary dormancy in buffalograss seeds. They also indicate that a 48-h water treatment can effectively reverse loss of germination in buffalograss seed lots that previously underwent a priming process, but develop secondary dormancy under storage.

Hormone studies. Data indicated that ABA plays a crucial role in the induction and maintenance of seed dormancy when its levels are elevated, and that increased GA levels (and lower ABA levels) encourage seed germination (Finch-Savage and LeubnerMetzger, 2006; Hilhorst et al., 2010; Hoang et al., 2013; Rodriguez-Garcia et al., 2009). Data indicated that poor germination $(<10 \%$ germination) of nontreated buffalograss seeds could be overcome by nitrate or water priming, and that secondary dormancy of primed seeds required a fresh priming treatment, suggestive of changes in hormone content that either prevented or permitted germination. On the basis of these observations, hormone profiles of buffalograss seed were conducted to access whether elevated levels of GA and decreased levels of ABA were present following the postharvest treatment.

Three independent hormone profiling experiments were conducted and the data were pooled before statistical analysis with a germination test treated as a random effect. Seed germination was almost doubled in NE07-01 seeds when the 24-h water treatments were compared with the 24-h nitrate treatments; however, no further improvements in germination were observed for either seed lots by increasing the soaking time from 24 to $48 \mathrm{~h}$ (Fig. 1). Regardless of soak time, ABA levels in Sundancer responded to $\mathrm{KNO}_{3}$ but $\mathrm{ABA}$ levels in NE07-01 remained relatively unchanged. Regardless of cultivar, levels of ABA were significant for both treatment and duration (Fig. 2). These data suggest that seed

A

B

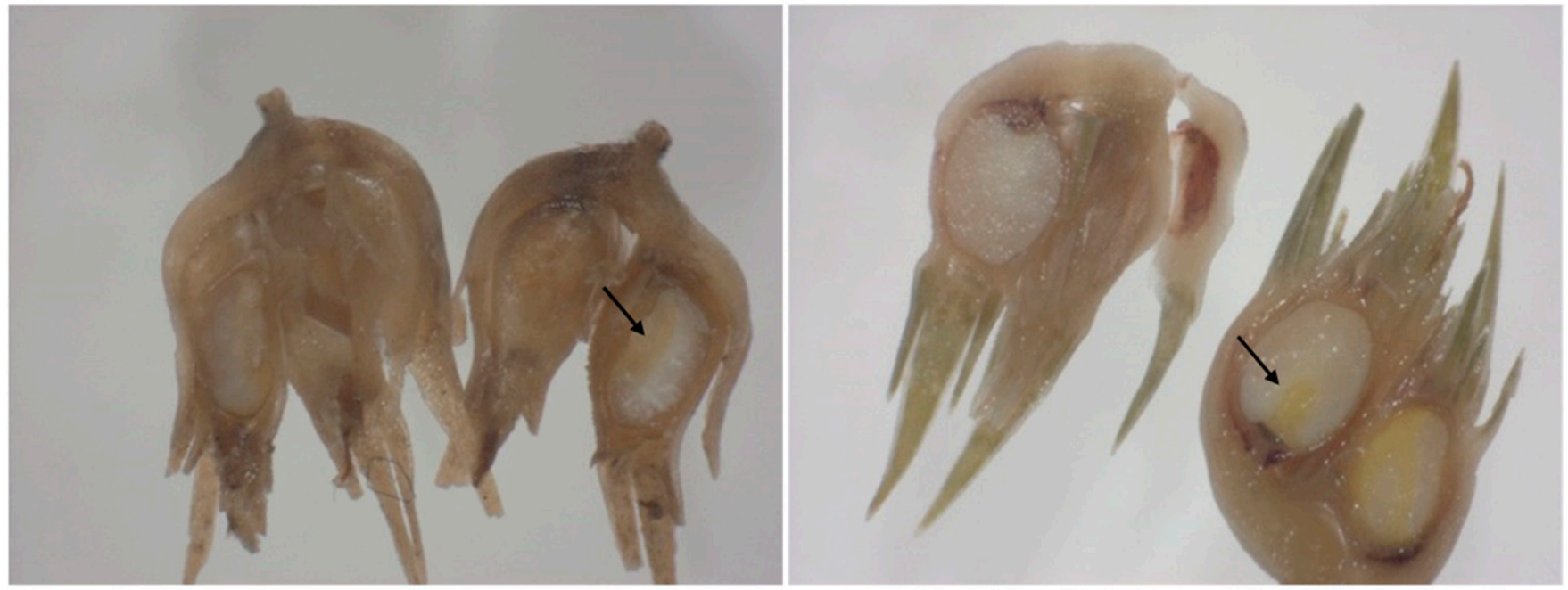

C

D

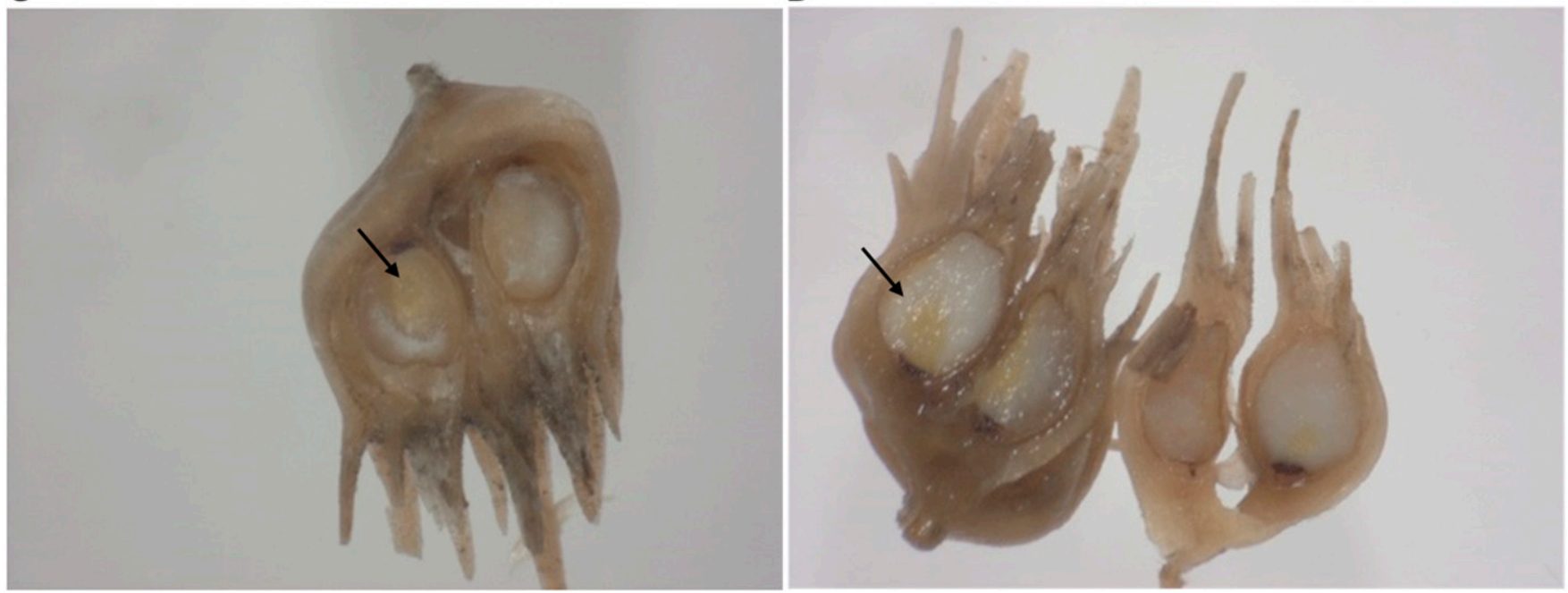

Fig. 5. Sundancer buffalograss burs spliced in half following a (A) 24-h water soak, (B) 48-h water soak, (C) 24-h 0.05 м potassium nitrate (KNO ${ }_{3}$ ) soak, and (D) 48-h $0.05 \mathrm{M} \mathrm{KNO}_{3}$ soak indicating the water and $\mathrm{KNO}_{3}$ treatments alter the bur coat to encourage seed germination. Arrows indicate evidence of increased hydration as a lustrous sheen on the cut caryopses and changes in the reflective properties of the endosperm, from white (A) as compared with regions of yellowish color $(\mathbf{B}-\mathbf{C})$. 
ABA contents were not influencing germination rates, at least for these two divergent buffalograss seed lots, but that the $24-\mathrm{h} \mathrm{KNO}_{3}$ treatments were influencing other aspects of the bur/caryopses interactions.

In NE07-01 seed, GA levels were unaffected by soaking treatment; however, GA levels did increase over soaking duration (Fig. 3). Sundancer seed responded oppositely, showing no response to soaking duration, but showing decreased GA levels between water and $\mathrm{KNO}_{3}$ treatments (Fig. 3). Data obtained for GA levels in primed seeds failed to show any significant interactions between GA content and germination levels as well (Figs. 1 and $3)$. Collectively it would appear that conditions in primed burs favor germination, and certainly observed levels of GA and ABA were not major determinants of this process.

In contrast to $\mathrm{ABA}$ and $\mathrm{GA}$ hormone profiles, SA, jasmonic acid (JA), and 12oxo-phytodienoic acid (OPDA) contents were consistently elevated in treated seeds compared with nontreated seeds (Fig. 4). All three hormones were increased with duration of treatment, $24 \mathrm{~h}$ as compared with $48 \mathrm{~h}$, and consistently 48 -h treatment with $\mathrm{KNO}_{3}$ significantly increased seed content of SA, JA, and OPDA in both seed sources (Fig. 4). However, germination levels of seeds treated with $\mathrm{KNO}_{3}$ for $48 \mathrm{~h}$ did not reflect the increase in hormone concentration levels at the same treatment. In bromegrass, JA levels are known to inhibit germination, especially in the presence of ABA (Wilen et al., 1994). For the two sources of buffalograss seeds evaluated, the relationships between plant hormones, priming, and germination appear to be more complex. It is possible that the after-ripening process that occurs between harvest and treatment had already elicited physiological changes in burs and enclosed caryopses in buffalograss seeds especially in the levels of ABA and GA. Thus, priming did not dramatically affect levels of these two hormones, but functionally changed other properties of the bur and bur/caryopses interface.

Caryopses hormone profiling. When initial hormone profiles were conducted, both whole burs and separated caryopses were tested to verify that hormones could be detected in the seed. Replicates of caryopses, like the whole burs, were treated with water and $\mathrm{KNO}_{3}$. The caryopses showed very little difference in the GA levels between the water-treated and $\mathrm{KNO}_{3}$-treated seed, whereas GA levels were magnified between seeds of the two treatments, showing that the bur coat is a major factor affecting buffalograss seed germination. ABA levels remained relatively unchanged between water and $\mathrm{KNO}_{3}$-treated seed; however, levels were magnified in the caryopses from water-treated seed vs. $\mathrm{KNO}_{3}$ treated seed. The fact that high germination was seen for caryopses obtained from treated burs would support a role for treatment, specifically $\mathrm{KNO}_{3}$ in changing the properties of the bur. Overall, experiments did not reveal a significant difference in hormone profiling between intact burs and isolated caryopses.
Water infiltration tests on seed. Water infiltration tests were conducted on the untreated, water-treated, and $\mathrm{KNO}_{3}$-treated seeds to explore potential changes in the properties of the bur. Differences were observed in the water infiltration rates among the three treatments. The time recorded for water absorption was significantly longer for nontreated seeds than water-treated seed, which was also significantly longer than the $\mathrm{KNO}_{3}$-treated seed (Table 1). Results revealed that the germination mechanism in these buffalograss seeds was not a result of hormone levels and ratios as suggested by Villiers and Wareing (1964), but more dependent on the physiochemical properties of the bur. Alteration of these properties was most evident with $\mathrm{KNO}_{3}$ treatments, although priming with water by itself was adequate to obtain consistent germination for some seed lots.

In addition, seeds were cut in half to observe any visible changes in the endosperm or embryos of the caryopses within the bur following 24 and $48 \mathrm{~h}$ water or $0.05 \mathrm{M} \mathrm{KNO} 3$ treatments (Fig. 5). Endosperm tissues in seeds soaked in water for $24 \mathrm{~h}$ did not appear to be hydrated and had minimal other observable changes (Fig. 5A). However, 24- or 48-h $\mathrm{KNO}_{3}$ treatments, and the 48-h water treatment appeared to have permitted the hydration of the caryopses and show some signs of initial breakdown of starch (yellowing of the endosperm) documenting germination progress in these caryopses. Figure 5 provides visible evidence that extended water $(48 \mathrm{~h})$ and $\mathrm{KNO}_{3}$ treatments had altered the properties of the bur coat enabling gas and water exchange.

\section{Conclusion}

Results indicate that $\mathrm{KNO}_{3}$ alters the bur coat in some capacity that encourages germination. It is a goal for future research to find the inhibitory compound(s) in burs that impact germination of buffalograss (and potentially other native grasses), and to discover the mechanism by which $\mathrm{KNO}_{3}$ interacts with the bur coat.

Our study calls to question the necessity of the $\mathrm{KNO}_{3}$ treatment typically used to break seed dormancy in buffalograss. Water, in many germination tests, produced similar germination levels, to that of $\mathrm{KNO}_{3}$, as seen particularly in the Sundancer germination results. In work done by Leon Wenger in the 1940s, germination tests also yielded results that supported both water and $\mathrm{KNO}_{3}$ as viable treatments (Wenger, 1941, 1943). The standard treatment for buffalograss today originated from Wenger's work over seven decades ago. In that amount of time, new turf and forage-type buffalograss cultivars have been released without testing the treatment. Though long-term storage effects of the treatments warrant further research, it is important to recognize the changes to the seedcoat induced by the seed treatments. The need for future research on seed dormancy is not only important for buffalograss, but also for other ornamental and amenity grasses that thrive with little inputs in areas where the need for resource conservation exists.

\section{Literature Cited}

Adkins, S.W., S.M. Bellairs, and D.S. Loch. 2002. Seed dormancy mechanisms in warm season grass species. Euphytica 126:13-20.

Ahring, R.M. and G.W. Todd. 1977. The bur enclosure of the caryopses of buffalograss as a factor affecting germination. Agron. J. 69:15-17.

Amen, R.D., G.E. Carter, and R.J. Kelly. 1970. The nature of dormancy and germination in the salt marsh grass Distichlis spicata. New Phytol. 69:1005-1013.

Banovetz, S.J. and S.M. Scheiner. 1994. Secondary seed dormancy in Coreopsis lanceolate. Amer. Midl. Nat. 131:75-83.

Baskin, C.C. and J.M. Baskin. 1998. Seeds: Ecology, biogeography and evolution of dormancy and germination. Academic Press, San Diego, CA.

Baskin, J.M. and C.C. Baskin. 2004. A classification system for seed dormancy. Seed Sci. Res. 14:1-16.

Bewley, J.D. 1997. Seed germination and dormancy. Plant Cell 9:1055-1066.

Bewley, J.D. and M. Black. 1985. Seeds: Physiology of development and germination. Plenum Press, New York, NY.

Crocker, W. 1916. Mechanics of dormancy in seeds. Amer. J. Bot. 3:99-120.

Finch-Savage, W.E. and G. Leubner-Metzger. 2006. Seed dormancy and the control of germination. New Phytol. 171:501-523.

Finkelstein, R., W. Reeves, T. Ariizumi, and C. Steber. 2008. Molecular aspects of seed dormancy. Annu. Rev. Plant Biol. 59:387-415.

Foley, M.E. 1999. Genetic model for dormancy in wild oat. Seed biol: Advanced and applications, p. 323-327. CABI Publishing, Wallingford, UK.

Hilhorst, H.W.M. 1990. Dose-response analysis of factors involved in germination and secondary dormancy of seeds of Sisymbrium officinale. Plant Physiol. 94:1096-1102.

Hilhorst, H.W.M. 1998. The regulation of secondary dormancy. The membrane hypothesis revisited. Seed Sci. Res. 8:77-90.

Hilhorst, H.W.M. 2007. Definitions and hypotheses of seed dormancy, p. 50-71. In: K.J. Bradford and H. Nonogoki (eds.). Seed development, dormancy, and germination. Blackwell Publishing, Oxford, UK.

Hilhorst, H.W.M., W.E. Finch-Savage, J. Buitink, W. Bolingue, and G. Leubner-Metzger. 2010. Dormancy in plant seeds, p. 43-67. In: E. Lubzens, J. Cerda, and M. Clarck (eds.). Topics in current genetics. Springer, Heidelberg, Germany.

Hoang, H.H., B. Sotta, E. Gendreau, C. Bailly, J. Leymarie, and F. Corbineau. 2013. Water content: A key factor of the induction of secondary dormancy in barley grains as related to $\mathrm{ABA}$ metabolism. Physiol. Plant. 148:284-296.

Ibarra, S.E., R.S. Tognacca, A. Dave, I.A. Graham, R.A. Sanchez, and J.F. Botto. 2016. Molecular mechanisms underlying the entrance in secondary dormancy of Arabidopsis seeds. Plant Cell Environ. 39:213-221.

Krizek, D.T., M.J. Camp, S.R. Maxon, G.C. Meyer, J.C. Ritchie, K.M. Davis, and M.L. McCloud. 2000. Comparative germination of 1998 and 1999 lots of germtec II treated eastern gamagrass seed after 28 days in the greenhouse and laboratory. Eastern Native Grass Symposium.

Kucera, B., M.A. Cohn, and G. Leubner-Metzger. 2005. Plant hormone interactions during seed dormancy release and germination. Seed Sci. Res. 15:281-307.

Letey, J. 1969. Measurement of contact angle, water drop penetration time, and critical 
surface tension. Proc. Symp. on WaterRepellent Soils, 6-10 May 1968, University of California, Riverside, CA, 43-47.

Luttgeharm, K.D., M. Chen, A. Mehra, R.E. Cahoon, J.E. Markham, and E.B. Cahoon. 2015. Overexpression of Arabidopsis ceramide synthases differentially affects growth, sphingolipid metabolism, programmed cell death, and mycotoxin resistance. Plant Physiol. 169(2):1108-1117.

Pozarnsky, T. 1983. Buffalograss: Home on the range, but also a turfgrass. Rangelands 5:214216.
Riordan, T.P., P.G. Johnson, R.E. Gaussoin, and J.F. Svoboda. 1997. Seedling germination and establishment of buffalograss caryopses vs. burs. Intl. Turfgrass Soc. Res. J. 8:749756.

Rodriguez-Gacio, M.C., M.A. Matilla-Vázquez, and A.J. Matilla. 2009. Seed dormancy and ABA signaling. Plant Signal. Behav. 4:10351048.

Villiers, T.A. and P.F. Wareing. 1964. Dormancy in fruits of Fraxinus excelsior. J. Expt. Bot. 16:533-544.
Wenger, L.E. 1940. Inflorescence variation in buffalograss, Buchloe dactyloides. Amer. Soc. Agron. J. 32:274-277.

Wenger, L.E. 1941. Soaking buffalograss seed to improve its germination. Amer. Soc. Agron. J. 33:135-141.

Wenger, L.E. 1943. Planting buffalo grass seed. Kan. Agr. Expt. Sta. Res. Bul. 321.

Wilen, R.W., B.E. Ewan, and L.V. Gust. 1994. Interaction of abscisic acid and jasmonic acid on the inhibition of seed germination and the induction of freezing tolerance. Can. J. Bot. 72(7):1009-1017. 